\title{
Regulating advance directives at the Council of Europe
}

\author{
Andorno, Roberto
}

Posted at the Zurich Open Repository and Archive, University of Zurich ZORA URL: https://doi.org/10.5167/uzh-68937

Book Section

Accepted Version

Originally published at:

Andorno, Roberto (2012). Regulating advance directives at the Council of Europe. In: Negri, Stefania. Self-determination, dignity and end-of-life care: regulating advance directives in international and comparative perspective. Leiden: Brill, 73-85. 
In: Stefania Negri (ed.), Self-Determination, Dignity and End-of-Life Care. Regulating Advance Directives in National and International Law, Series: Queen Mary Studies in International Law, Leiden, Brill Academic Publishers, 2012, p. 73-85

\title{
REGULATING ADVANCE DIRECTIVES AT THE COUNCIL OF EUROPE
}

\author{
Roberto Andorno ${ }^{(*)}$
}

\section{Introduction}

It is now widely accepted that patients' right to informed consent presupposes the possibility for them to refuse treatments, especially when these are perceived by them as excessive, futile or psychologically harmful. Both consent and refusal of consent are indeed envisaged today as two different expressions of the same patients' right to self-determination. Thus, refusals of medical treatments are also to be respected, even if they might adversely affect patients' health or shorten their life.

But a problem emerges when patients have lost their decision-making capacity due to a condition that is not likely to be reversible (e.g. persistent vegetative state, severe head injury, dementia, etc.). Who shall decide for them in such cases? Which criteria should be used in the decision-making process? What if family members disagree about treatments to be provided or withheld? What if doctors and patient's relatives have different views on what is best for the patient? Here is where the potential utility of advance directives comes into play; they can take two different forms, which are not necessarily exclusive of each other, since they both can be combined in the same document:

a) The living wills, which are (usually written) instructions that specify ahead of time personal preferences regarding the provision -or the withholding- of particular treatments in the event that the individual becomes unable to make decisions in the future;

b) The lasting (or durable) powers of attorney for health care, which allow individuals to appoint someone as a "health care proxy" (for example a trusted

Senior Research Fellow at the School of Law of the University of Zurich, Switzerland. Email: roberto.andorno@rwi.uzh.ch 
relative or friend) to make health care decisions on their behalf once they lose the ability to do so.

The key issue is however whether or to what extent domestic legislation recognizes the validity and efficacy of advance directives. At present, European countries have very different or no legal standards at all on this matter. The current situation may create problems with the increasing crossborder movement of EU citizens. In addition, the growing of the aging population of European societies is likely to create an increased demand for advance directives in the next years. What seems to be clear is that a reliable solution has to be found to solve the practical problem posed by advance directives made in one European country and implemented in another.

Since the end of the 1990s, especially with the adoption of the Convention on Human Rights and Biomedicine (thereafter "Biomedicine Convention" or "Oviedo Convention"), the Council of Europe has made significant efforts to set up common standards in this field. This paper will first outline the strengths and shortcomings of Article 9 of the Biomedicine Convention, which specifically deals with living wills. It will then analyze the Council of Europe's Recommendation (2009)11 on continuing powers of attorney and advance directives for incapacity.

\section{Advance directives in the Biomedicine Convention}

\section{a. The Biomedicine Convention as a framework instrument}

The Council of Europe is indisputably the leading intergovernmental organization in the development of common European norms relating to bioethics. It is worth remembering that this body, which gathers at present 47 Member States (that is, virtually all European countries), was established a few years after the end of the Second World War to promote respect for democracy and human rights across Europe. To achieve this purpose, it adopted in 1950 the European Convention on Human Rights and subsequently various mechanisms aimed at ensuring respect for human rights in the old Continent such as the European Court of Human Rights.

It was the same foundational goal of promoting human rights that led the Council to address various bioethical issues since the early 1980s. From that time, the Parliamentary Assembly (the deliberative body of the Council of Europe) as well as the Committee of Ministers (composed by all Foreign Ministers of Member States) issued a number of recommendations on topics such as genetic engineering, embryo research, patients' rights, health databases, etc.

The most significant step in this process was undoubtedly the adoption of the Biomedicine Convention. After four years of discussion and consultations, the Convention was approved by the Committee of Ministers on 19 November 1996 and opened for signature in Oviedo on 4 April 1997. The Convention 
entered into force in December 1999, following the fifth ratification, that of Spain. ${ }^{1}$

The importance of the Biomedicine Convention lies in the fact that it is the only binding intergovernmental instrument that comprehensively addresses the link between human rights and biomedicine. The Convention's purpose, as indicated by its Preamble, is to specifically safeguard respect for human dignity and human rights with regard to the applications of biology and medicine. In other words, this instrument can be regarded as an extension of human rights law into the biomedical field. ${ }^{2}$

For a correct analysis of the Convention it is necessary to keep in mind that it has been conceived as a framework instrument. This means that it only includes general guiding principles and does not intend to offer a detailed regulation of biomedical issues. The Convention only attempts to identify the most basic legal standards that are accepted by all European countries in order, first, to create a solid basis for further developments by means of additional protocols, and second, to urge states to enact consistent legislation. ${ }^{3}$ This minimalist approach was chosen for both substantive and practical reasons, that is, for the need to respect the cultural specificities of each country, and for the impossibility of a deeper consensus, respectively.

\section{b. Article 9 of the Biomedicine Convention}

There is a striking contrast between the decades-long attention paid to advance health care planning in the United States and the only recent interest given to it in Europe. In the U.S., the public debate about the scope and legal efficacy of advance directives started around thirty years ago. The American lawyer Luis Kutner seems to have been the first to suggest the concept of living wills in 1967.4 The Congress passed in 1990 the Patient SelfDetermination Act, which requires hospitals to ask every patient on admission whether they have completed an advance directive (either a living will or a durable power of attorney, or both) and, if so, to bring a copy to the hospital. If the patient does not have an advance directive but would like more information about these documents, hospitals must also provide the information. At present, all U.S. states have specific laws recognizing the use of advance directives and often provide a model document that may (or in some states must) be followed. ${ }^{5}$

\footnotetext{
${ }^{1}$ At the time of this article (November 2010), the Biomedicine Convention was signed 34 countries and ratified by 23 of them. See the updated list of signatures and ratifications at: http://www.coe.int/bioethics (accessed on 25 November 2010).

2 See Roberto Andorno, "The Oviedo Convention: A European Legal Framework at the Intersection of Human Rights and Health Law”, Journal of International Biotechnology Law, 2005, n² 2, p. 133 143.

3 Four additional protocols have already been adopted: on human cloning (1998), on organ transplantation (2002), on biomedical research (2005), and on genetic testing for health purposes (2008).

${ }^{4}$ See Alasdair MacLean, “Advance Directives and the Rocky Waters of Anticipatory DecisionMaking”, Medical Law Review, 2008, vol. 16, n 1 , p. 1.

5 See the complete list of model documents state by state at: http://www.uslegalforms.com/livingwills/ (accessed on 25 November 2010). In the US operates a privately held organization (U.S. Living Will Registry) that electronically stores advance directives
} 
In contrast, the attention given to advance directives in most European countries is very recent. Only in the last few years some of states have enacted specific laws to regulate this matter, while others are still reluctant to do so. ${ }^{6}$ The fact is that it is still unusual in Europe to base clinical decisions regarding incompetent patients on their previously expressed wishes.

The Biomedicine Convention only covers this issue in Article 9, which provides that:

"The previously expressed wishes relating to a medical intervention by a patient who is not, at the time of the intervention, in a state to express his or her wishes shall be taken into account."

This provision is certainly important as it marks the first recognition of the value of advance directives in a common European binding instrument. Although European countries are not obliged under Article 9 to give legally binding force to advance directives, they must at least recognize their advisory effect. Professor Adriano Bompiani, who was directly involved in the drafting of the Convention as Italian representative, points out that the expression "taken into account" used in Article 9 was adopted as a way to find a balance between, on the one hand, due consideration of the patient's wishes expressed in advance, and on the other, a technical, objective assessment of the current clinical situation of the patient and of the elementary duties of the doctor to choose the more adequate treatment according to the current circumstances. ${ }^{7}$

While this compromise formula is understandable in the light of the conflicting views of European countries on this matter, the fact is that the wording of Article 9 is problematic in the sense that the expression "to take into account", without any additional clarification, is too ambiguous and can be interpreted in very different ways. ${ }^{8}$ It would have been preferable to have clearer guidance for doctors as to what extent, or under what conditions, patients wishes expressed in advance must be implemented. It is obvious that if health care professionals could arbitrarily decide, without giving any serious reason, not to comply with patients' preferences, the patient's effort of making an advance directive becomes useless. This is the key point of the current controversy, which becomes also visible in the use of the wording "previously expressed wishes" instead of "advance directives" in the title of Article 9. This latter expression, which does appear neither in the Convention nor in its

and makes them available to health care providers across the country. See http://www.uslivingwillregistry.com/ (accessed on 25 November 2010).

6 See Roberto Andorno, Nikola Biller-Andorno and Susanne Brauer, "Advance Health Care Directives: Towards a Coordinated European Policy?", European Journal of Health Law, 2009, vol. 16, n 3, p. 207-227.

${ }^{7}$ Adriano Bompiani, Consiglio d'Europa, diritti umani e biomedicina. Genesi della Convenzione di Oviedo e dei Protocolli, Rome, Edizioni Studium, 2009, p. 86.

${ }^{8}$ See, for instance, Dominique Manaï, "Images du droit du patient au miroir de la Convention européenne pour les droits de l'homme et la biomédecine", in: F. Werro (ed.), L'européanisation du droit privé? Vers un code civil européen? Fribourg, Editions Universitaires de Fribourg, 1998, p. 120; Hans-Ludwig Schreiber, "The European Ethical Convention: Legal Aspects”, in: A. Schauer, H. L. Schreiber and Z. Ryn (eds.), Ethics in Medicine, Göttingen, Vandenhoeck \& Ruprecht, 2001, p. 247; Gilbert Hottois, "A Philosophical and Critical Analysis of the European Convention of Bioethics", Journal of Medicine and Philosophy, 2000, vol. 25, n 2, p. 139. 
Explanatory Report, was not included on the ground that it presupposes the binding nature of such documents.

Another shortcoming of Article 9 is that it is exclusively focused on living wills, but totally ignores the other form that advance directives may take (the continuing power of attorney). This becomes especially clear when one reads the Explanatory Report to the Convention, which never refers to the possibility of appointing a health care proxy. ${ }^{9}$ The Council of Europe's Recommendation (2009)11, as will be mentioned hereafter, attempts to fill this lacuna.

It should also be mentioned that the Explanatory Report to the Convention does not resolve the ambiguity of Article 9. It only states that the expression "taken into account" "does not mean that previously expressed wishes should necessarily be followed" and provides two examples to illustrate why in some circumstances the practitioner may have good reasons not to comply with the patient's wishes on the grounds that they do not apply anymore to the situation at hand: a) when they have been expressed a long time before the intervention; b) when medical technology has made significant progress since the time when the advance directive was signed and it can be reasonably assumed that, in the present circumstances, the will of the patient would have been different. ${ }^{10}$ In light of these examples it would seem that the spirit of Article 9 is that doctors cannot act arbitrarily, i.e., they need to have good reasons to disregard the patient's legitimate wishes expressed in an advance directive. The problem is that this basic principle has not been explicitly included in the Convention itself, nor there is any indication as to what reasons can be validly given by health care professionals for not complying with the patient's explicit will.

Therefore, the key point is whether it would be possible (and desirable) to reach at least a minimum consensus among European countries on the two following issues:

- The minimal formal requirements for the validity of advance directives such as for instance the individual's legal capacity and freedom of choice at the time of its drafting; his/her incompetence at the time of its implementation; absence of revocation in the meantime; the need of a previous consultation with a health care professional, etc.

- The legal effect of advance directives, which directly relates to extent to which doctors are obliged to comply with patients' preferences and the reasons they can legitimately give for not doing so. Among the possible reasons the following can be mentioned: that the patient's will is contrary to law; that the document was written too many years before its implementation; that there have been significant advances in medical sciences that are relevant to the advance directive in question; that there are some serious evidence suggesting that the patient would have a different view had he/she had adequate knowledge of the current circumstances.

\footnotetext{
${ }^{9}$ See paragraphs 60 to 62 .

${ }^{10}$ Explanatory Report to the Convention on Human Rights and Biomedicine, paragraph 62.
} 


\section{The Recommendation (2009)11}

\section{a) General features of the recommendation}

The Council of Europe's Committee of Ministers adopted on 9 December 2009 the Recommendation (2009)11 on "continuing powers of attorney and advance directives for incapacity". This document is of great relevance regarding advance directives as it seeks to fill the two above mentioned gaps of the Biomedicine Convention (the vagueness of Article 9 regarding the legal efficacy of living wills, and the lack of regulation of continuing powers of attorney).

Before focusing on the analysis of the recommendation, two preliminary remarks ought to be made. The first is that the scope of the recommendation is actually much broader than health care, since it also covers decisions regarding welfare, and economic and financial matters. The second is that the recommendation uses the expression "advance directives" in a narrow sense, as a synonym for "living wills". Continuing powers of attorney are treated as a separate category. In order to avoid misunderstandings, this paper will use below the expression "advance directive" in this narrow meaning.

The recommendation consists of a preamble and seventeen principles. It makes it clear from the very beginning that its overarching scope is "to promote self-determination of capable adults in the event of their future incapacity, by means of continuing powers of attorney and advance directives" (Principle 1.1). "Self-determination", which is mentioned five times in the whole recommendation, clearly embodies the key value of this document.

The preamble draws attention to previous international and regional instruments relating to this matter, in particular, to the Recommendation (99) 4 of 23 February 1999 on principles concerning the legal protection of incapable adults. This latter document is recognized as a "valuable and up-todate international instrument" in this field. However, it is also recognized that there is a need to build upon the principles of subsidiarity and necessity already contained in the Recommendation (99)4, and to "supplement" it by giving prominence to the principle of self-determination. There is indeed a substantive difference between both documents: the 1999 recommendation deals with measures of protection provided by competent authorities (i.e., courts), while the 2009 one covers decisions made privately by the individuals concerned themselves, either by appointing a proxy or by making an advance directive. According to the recommendation, this new strategy for protecting the interests of incapacitated adults should be given priority over other measures of protection (Principle 1.1), not only more because it is more in line with the principle of self-determination, but also because it avoids timeconsuming and sometimes costly, sensitive and burdensome judicial and administrative proceedings. ${ }^{11}$

Nevertheless, the two means of self-determination covered by the 2009 recommendation do not seem to be put on an equal level: the document

\footnotetext{
11 The Preamble notes that "that in some member states continuing powers of attorney are a preferred alternative to court decisions on representation".
} 
appears to give preference to the use of surrogate decision-making over living wills: while most of its provisions (Principles 3 to 13) concern continuing powers of attorney, living wills receive little attention: only the last four principles (14 to 17) deal with them, and in a very succinct way. It is true that continuing powers of attorney cover a broad spectrum of possible uses (financial, economic, welfare and medical ones) and therefore need to be regulated in more detail, while living wills are particularly (though not exclusively) conceived to serve health care purposes. ${ }^{12}$ But there are more substantive reasons explaining this disparity. First of all, European states are well familiarized with the use of powers of attorney, which have a very long tradition in the continent (beginning with the contract of mandatum in Roman law), even if only recently they began to be used for making decisions about medical treatment. In contrast, living wills are an entirely new and more controversial way of stating health care preferences ahead of time. Secondly, the implementation of living wills raises difficult (and sometimes unsolvable) problems of interpretation, which do not exist, or are less serious, with surrogate decision-making. Thirdly, some states are concerned with the possibility that living wills could be misused, leading to the neglect of vulnerable or elderly patients, even maybe for purely economic reasons. In addition, it must be noted that over the last years, doubts have been raised about the real utility of living wills, especially when they are drafted in general terms (as it is often the case). Looking back at the long, and according to them, unsuccessful experience with living wills in the United States, some experts suggest that it is time to change the strategy and give priority to continuing powers on attorney, or at least to a combination of living wills and continuing powers of attorney. ${ }^{13}$

\section{b. Continuing powers of attorney}

As it was just mentioned, one of the well-known problems with living wills is the difficulty of drafting a sufficiently specific document without knowing the particular condition in which one will be placed. When there is already a diagnosis that makes a serious condition predictable, the spectrum of decisions regarding alternative treatments is relatively limited and easy to handle. But how can healthy individuals decide in advance in specific terms the kind of treatments they would like to have or not, if they do not know in which situation they will be placed? In contrast, continuing powers of attorney have the great advantage of allowing the doctor to enter into a dialogue with a person (the attorney, or proxy), rather than being merely confronted with a piece of paper, which necessarily has to be interpreted. The proxy can directly discuss with the health care professional about the various available options, about the benefits and risks of each one, and this taking into account the concrete circumstances in which the patient is placed.

\footnotetext{
12 The Explanatory Memorandum to the Recommendation is explicit in this regard: "The most important type of legally regulated advance directives concerns health issues" $\left(n^{\circ} 65\right)$.

${ }^{13}$ Angela Fagerlin and Carl E. Schneider, "Enough. The Failure of the Living Will", Hastings Center Report, 2004, vol. 34, n 2, p. 30-41.
} 
The proper role of the proxy in the decision making-process can differ depending upon which modality of surrogate decision is adopted. There are basically two different models:

a. Substituted judgement, where proxies, based on their knowledge of the patients' preferences, make a judgement intended to reflect, as closely as possible, the judgement the patients would make if they were competent. This approach attempts to simulate an incompetent patient's autonomous decision by considering the personal values and preferences held by the patient and is therefore justified by the principle of respect for autonomy.

b. Best interests, where the proxy makes an assessment of the patient's best interests and decides based on that assessment. In this approach, the proxy must consider, from an objective point of view, what course of action would result in the greatest benefit and least harm to the patient. Here the proxy does not need to imagine the situation from the incompetent patient's perspective, but rather makes a decision on behalf of the patient. This approach is justified by the principles of beneficence and non-maleficence. ${ }^{14}$

These two models of surrogate decision-making can be combined, but in such cases it is advisable to make it clear which approach has the priority and which one is only subsidiary to the first one. For instance, when proxies have no basis on which to make a reasonable judgment about the patient's preferences, it is reasonable to encourage them to consider the best interests of the patient. On the contrary, the attempt to simultaneously combine both approaches risks creating confusion about the proper role of the proxies and about the criteria they should use in making a decision. ${ }^{15}$ It may happen that both criteria appear to be in conflict. What if the proxy considers that a particular treatment is in the best interest of the patient, but it seems to be contrary to the patient's wishes?

In this regard, the Recommendation (2009)11 is not sufficiently clear. On the one hand, proxies are required to make their decisions in accordance with the continuing power of attorney and in the (best) interests of the patient (Principle 10.1). On the other hand, they must also take into account, "as far as possible", "the wishes and feelings" of the patient and give them "due respect" (Principle 10.2). How can both requirements be harmonized? A possible way out of this dilemma is to consider that the best interest of the patient, which is mentioned in the first paragraph and without any particular condition, is a general principle that should always guide the proxy's decision. This standard embodies the basic guiding value for surrogate decision-making, and offers the conceptual framework for the proxy's decisions. On the contrary, the "wishes and feelings" of the patient are an element among others that the proxy must take into account, "as far as possible", to determine what is in the best interest of the patient.

\footnotetext{
${ }^{14}$ John E. Snyder and Candace Gauthier, Evidence-Based Medical Ethics. Cases for Practice-Based Learning, Charlotte, North Carolina, Humana Press, 2008, p. 19.

${ }^{15}$ See Anthony Wrigley, "Proxy consent: moral authority misconceived", Journal of Medical Ethics, 2007, vol. 33, n 9, p. 527-531.
} 
It should be acknowledged, however, that the concept of "best interest of the patient" is highly abstract and can be interpreted in different ways when confronted with the need to make a concrete decision. For instance, can decisions leading to the withholding or withdrawal of a treatment because it regarded as futile or unduly burdensome be in the best interests of the patient? The most common answer to this question seems to be yes, even if it is foreseen that such a decision may also hasten that person's death. ${ }^{16}$ However, in practice things are not always that clear-cut. In this regard, the UK Mental Capacity Act, passed in 2005, offers a very detailed and helpful guidance for identifying what might be, or not, in the best interests of the patient (Section 4). Especially important is Section 4.5, which provides, in relation to life-sustaining treatments, that the individual making the decision "must not, in considering whether the treatment is in the best interests of the person concerned, be motivated by a desire to bring about his death". This means that the notion of "best interests" relates to the benefits and burdens of the treatment itself (and may eventually justify the withholding or withdrawal of life-sustaining measures), but such decisions should not reflect a judgement that the patient's life is not worth living. Thus, in the effort to determine what is in the best interests of the patient, a very delicate balance is needed to prevent, on the one hand, futile or too burdensome treatments and, on the other hand, a slippery slope towards intentional killing of incapacitated patients by omission.

The definition of "continuing power of attorney" given by the Recommendation (2009)11 is somehow confusing, and needs a clarification. According to Principle 2.1, it is "a mandate given by a capable adult with the purpose that it shall remain in force, or enter into force, in the event of the granter's incapacity". The use of two different expressions ("remain in force" and "enter into force") obeys to the fact that the definition includes the point of time in which the power of attorney will become operative, and this varies depending on the purpose of the document: those for economic and financial matters may become effective immediately, and remain valid after the granter's incapacity; those for health, welfare and personal matters only will be in effect in the event of the granter's incapacity.

Under the recommendation, any competent individual, and not necessarily a family member, can be appointed as attorney (Principle 4.1). Granters can appoint more than one person, but in such cases they should indicate how the attorneys are to act (jointly, separately, jointly in relation to some matters and separately in relation to others, as substitutes, etc.) (Principle 4.2).

Regarding the formalities to be complied with, the recommendation requires that the power of attorney "shall be in writing" (Principle 5.1), and that the document shall explicitly state that it will become effective in the event of the granter's incapacity (Principle 5.2). Although the recommendation does not mention that the document must be signed, this seems to be an obvious requirement, especially considering that the attorney will have the

\footnotetext{
${ }^{16}$ I do not include in this statement the withdrawal of artificial nutrition and hydration of patients in persistent vegetative state, which remains controversial, as was shown by the cases of Terri Schiavo in the US and of Eluana Englaro in Italy.
} 
power to make decisions on matters of life and death pertaining to the granter. The recommendation leaves to the states to determine other formal requirements for the validity of the power of attorney (for instance, notarization, presence of witnesses, registration with a public office, etc.) (Principles 5.3 and 8).

\section{c. Advance directives}

Principle 2.3 defines advance directives (living wills) as "instructions given or wishes made by a capable adult concerning issues that may arise in the event of his or her incapacity". The use of two terms ("instructions" and "wishes") does not serve a merely rhetorical function: the word "instructions" is employed to refer to advance directives that are legally binding, while "wishes" is used to indicate that such documents have a merely advisory value. ${ }^{17}$ This double terminology, which also appears in Principle 15, shows well the deep disagreement between European countries concerning the legal effect to be given to advance directives.

The new recommendation does not bring to an end this lack of consensus. States are still left to decide whether advances directives should be legally binding or not. This does not mean that no progress has been made in this field since the Biomedicine Convention. Today there is a growing awareness of the importance of enhancing patients' self-determination and avoiding futile or disproportionate treatments. Precisely in an attempt to promote patients' autonomous decisions, a number of European countries have in recent years passed specific laws on advance directives, or are on the way of enacting legislation in this area. The Biomedicine Convention has played a role in this process, and there is no doubt that it has even had an impact on those countries that did not ratify it yet. But the fact is that disagreements still persist about the norms that should govern advance directives.

Interestingly, the terminology used in Principle 15 to refer to previously expressed wishes is slightly different from the one found in Article 9 of the Biomedicine Convention. While this latter provides that such wishes "shall be taken into account", the recommendation stipulates that they should be given "due respect". This latter wording sounds stronger than the one of the Biomedicine Convention. In this regard, it is interesting to note that some countries employ the verb 'to respect' in their domestic laws precisely in order to make advance directives binding. ${ }^{18}$ Was this difference in the wording deliberate or simply an oversight? The latter is more likely since it only

\footnotetext{
${ }^{17}$ Explanatory Memorandum to the Recommendation, $\mathrm{n}^{\circ} 178$.

${ }^{18}$ For instance, the new Article 372.2 of the Swiss Civil Code, adopted in 2008 and which will enter into effect in January 2013 provides that advance directives must be "respected" by the doctor and this is commonly interpreted as a recognition that they are prima facie binding. Such binding effect is not absolute as the doctors is not obliged to follow the patient's preferences if he or she considers that there are serious reasons to believe that they do not reflect anymore the patient's wishes in the current circumstances. The French version of Article 372.2 reads: "Le médecin respecte les directives anticipées du patient, sauf si elles violent des dispositions légales, ou si des doutes sérieux laissent supposer qu'elles ne sont pas l'expression de sa libre volonté ou qu'elles ne correspondent pas à sa volonté présumée dans la situation donnée."
} 
appears in the English version of the recommendation, while the French text employs the same verb that is used in Article 9 of the Biomedicine Convention ("prendre en compte", that is, "take into account").

Regarding the formalities to be observed, in general, advance directives do not necessarily have to be in writing. A person can communicate orally his or her preferences to family members, friends, medical staff, etc. However it is clear that a written decision is to be preferred over a verbal one. In any case, if the advance directive is intended to have binding effect, it should be in writing, or at least recorded in some way (Principle 16). States are also asked to address the issue of substantial changes in circumstances in order to determine how that will affect the validity of advance directives (Principle 15.2).

\section{Conclusion}

The Council of Europe has achieved two important milestones in the promotion of patients' self-determination regarding medical care to be implemented in the event of future decisional incapacity: the Biomedicine Convention and the Recommendation (2009)11. The former represents the first European binding instrument recognizing that living wills should have, at least, an advisory value and that therefore they must be "taken into account" by health care professionals. The latter is an attempt to further develop that recognition by means of a soft law instrument, and especially, to draw the attention of European states to an alternative and less controversial tool for planning health care in advance: the continuing power of attorney.

Further studies and discussion are needed to determine whether the Council of Europe has done all that it could in the promotion of health care decisions ahead of time, given the different and even opposed views among European countries, or whether it is desirable (and possible) to seek for greater substantive consensus on this matter. 